\title{
Towards a RBAC Workflow Model for Thesis Management
}

\author{
Kui Liu², Zhurong Zhou1*, Qianguo Chen³ ${ }^{3}$, Xiaoli Yang² \\ ${ }^{1}$ School of Computer and Information Science in Southwest University. \\ ${ }^{2}$ Experimental Teaching Center of International Studies in Southwest University, Chong Qing, China. \\ ${ }^{3}$ Center for Teaching Development in Chongqing Technology and Business University. \\ * Corresponding author. Email: zhouzr@swu.edu.cn. \\ Manuscript submitted November 6, 2014; accepted March 17, 2015. \\ doi: $10.17706 /$ jsw.10.4.480-490
}

\begin{abstract}
The traditional manual way of thesis management is increasingly satisfying the demand of thesis guidance and administrative management in the information age. To improve the traditional manual undergraduate thesis writing, guidance and administrative management process in Southwest University of China, a Role-based access control (RBAC) Workflow model for thesis management is developed. In the RBAC workflow model, role's authorization to users and permission's authorization to roles are activated by time-triggered and task-based principle. The thesis management system based on the RBAC Workflow model is available, and this system is evaluated by means of practical application. The comparison results of this system can effectively reduce the workload of undergraduate thesis work, monitor thesis writing and guidance, enhancing the informatization level of undergraduate thesis work massively.
\end{abstract}

Key words: RBAC, Workflow, Thesis management, time-triggered, task-based.

\section{Introduction}

Currently, at least in China, each student (either undergraduate or graduate) has to write a thesis to finally finish his (or her) studies since to complete a thesis is indeed an important practice course for students. At the moment, there is an imbalance between the number of teachers (thesis supervisors) and the number of students especially for undergraduate students because in China the number of undergraduate students is quite huge. For example, in the School of International Studies of Southwest university (of China), there are 579 undergraduate students, 112 graduate students, and 395 normal graduate students, who all need to complete a thesis in 2014 . Besides, there are 325 undergraduate students who come from other school minoring in English. Those students also need to complete thesis, but only 146 supervisors are available to guide all of them.

Because of such imbalance, one teacher is asked to guide a lot of students to finish their theses. In other words, it is time-consuming for a teacher to guide undergraduate students. Besides, a lot of roles such as managements, teachers and students are involved in the whole process of completing a thesis like assigning topics, guiding theses and reviewing drafts.

To summarize, there are at least four drawbacks in the traditional manual way of thesis management which are listed below:

1) Heavy Workload: The complete life-cycle of undergraduate thesis work process is a cumbersome, complicated and repeated workflow with a long span involving lots of people and many work links. In addition, managements need to arrange a great deal of theses' paper documents.

2) Low Level Information: Each stage of the undergraduate thesis work process will create many documents which are related closely to each other, so it is very difficult for Managements to collect, search and store 
various printed paper documents, We can use e-documents sometimes, but most of them are not systematically created to each other yet. In addition, it is inconvenient for students to submit paper. Not to mention that paper documents are not environmentally friendly.

3) Difficult Communication: To eventually finish a thesis, supervisors and students have to interact with each other frequently. However, some students are doing internship outside of campus and some teachers do not have a steady workplace, in that case, it is very difficult for teachers and students to communicate face-to-face with each other regularly. They can communicate through cellphone or network, but there is not perfect. It lacks reliability and security.

4) Lack of Effective Supervision: Traditional way of thesis writing and guidance which lacks effective supervision is based on face-to-face communication between supervisors and students, so it is not easy to urge supervisors and students to achieve each stage entirely and punctually. Because of the lack of supervision provided by a third-party, it often occurs that teachers and students like to find excuses to shift responsibilities about paper quality completion, which is a recurrent and unsolvable problem.

Because of the above problems, to successfully manage the theses of undergraduate students becomes extremely hard. Researchers and educators have been exploring various functional methods of thesis management, and there are various kinds of thesis management systems presented as follows:

Jun Xun [1] focused on a paper management system based on Ontology, Dao-Hua Yu [2] supported the idea of the web management of graduation thesis. Hong-ben Mao [3] proposed a graduation thesis intelligent management system based on .NET. Zhi-he Li [4] developed a thesis management system based on web. Xiao -yang Wen [5] studied the thesis management system based on workflow and role collaboration. Shi-rong Long [6] designed a thesis management system based on browser/server and workflow. However, most of them just studied the different thesis management systems, ignoring modeling or formalizing. And there are few actual application studies campared with the traditional manual way, therefore, it is controversial to evaluate the efficiency of deploying systems they proposed when solving problems which exist in a traditional manual way.

Thus, we focus on proposing an efficient approach in this paper to simplify the thesis management process. More specifically, we firstly develop a RBAC Workflow model for thesis management according to the characteristics of the complete life-cycle of thesis work. In the RBAC workflow model, role's authorization to users and permission's authorization to roles are activated by time-triggered and task-based principle. Then, we develop a system based on the RBAC Workflow model to electronically manage theses of undergraduate students. In addition, we practice a series of actual application studies to evaluate the efficiency of deploying our thesis management system.

In the rest of the paper, Section 2 discusses related work. Section 3 specifies the Role-based Access Control Workflow model for Thesis Management in which time-triggered and task-based rules are also taken into consideration by analyzing the thesis work process. An empirical study to evaluate the efficiency of deploying our thesis management system is shown in Section 4 and Section 5 gives our conclusions.

\section{Related Work}

Role-based access control (RBAC) was defined by Sanhu [7], is a form of mandatory access control. Xin Wen Zhang [8] recognized that Role-based access control model is an efficient access control model for large institutions, and held that most institutions have some business rules related to access control policy. Delegation of authority is among these rules. RBAC is aproven to be an increasingly commonplace technology for these institutions. In RBAC, access rights are associated with roles, and users are assigned appropriate roles, thereby they can acquire the corresponding permissions. The notion of role is an institutional concept. RBAC allows us to model security from the perspective of the institution, thus we can align security modelling to the roles and responsibilities in the institution. Most large institutions have some business rules related to access control policy such as need-to-know, separation of duty, rotation of sensitive job position and so on. Delegation of authority is an important one of these. Delegation means that a person gives all or part of his authority to 
somebody. Christine Liang [9] propoed a faster way to temporarily redirect the role based access control workflow processes.

Workflow which was defined by the Workflow Management Coalition [10] is concerned with the automation of procedures where documents, information or tasks are passed among participants according to a defined set of rules to achieve, or to contribute to, an overall business goal.

Workflow Management Systems are used to coordinate and streamline business process in an enterprise. Most of the workflow processes are developed with Role Based Access Control for security purposes. And, in recent years, many large institutions have used the Role Based Access Control Workflow Management System to manage their daily workflow [9].

Time-triggered system was proposed by Pont [11], A Time-Triggered system is a computer system that executes one or more sets of tasks according to a pre-determined task schedule. Implementation of a time-triggered system will typically involve use of a single interrupt that is linked to the periodic overflow of a timer. This interrupt may drive a task scheduler (a restricted form of real-time operating system). The scheduler will-in turn-release the system tasks at predetermined points in time [12].

Task-based teaching [13], [14] is a kind of teaching method which is based on the constructivism learning theory. This method has converted the traditional teaching principle into a multi-dimensional interactive teaching principle which focuses on solving problems and completing tasks. As a result, every student can propose a specific plan himself using shared knowledge and his own experience according to his understanding of the problem. In the meantime, each student is in a positive learning state.

\section{RBAC Workflow Model}

In this section, we specify the RBAC Workflow Model for thesis management by analyzing the complete life-cycle of thesis work process.

\subsection{The Workflow of Thesis Management}

Firstly, we present the workflow of the thesis management, which is shown in Fig. 1.

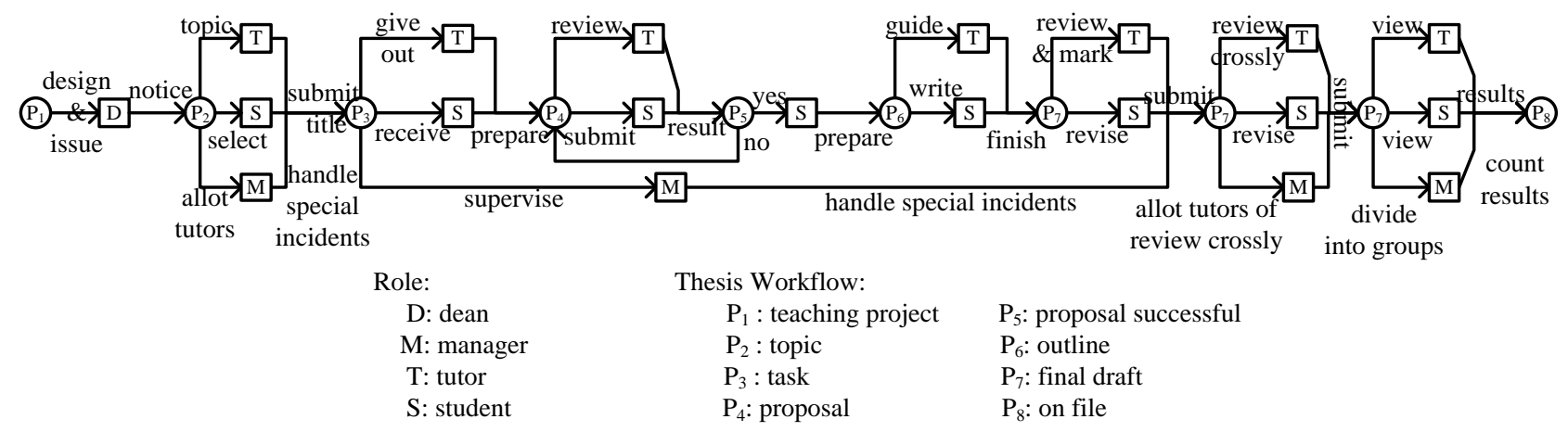

Fig. 1. Thse workflow of thesis management.

The thesis work process is a whole workflow, involving different roles, such as Management (Deputy Dean, Department Head, Teaching Secretary), teacher (Supervisor, Cross Reviewer, Member of Thesis Defense Committee), student (Undergraduate, Recorder of Thesis Defense). These roles chronologically complete all of thesis work task step by step. Of course, different roles are assigned different tasks; these assignments match the roles' permission authorization.

In the whole theses work process, the start and the end of each work stage will be triggered by time, and the operation for each period of each role will be recorded automatically and chronologically, so time-triggered principle is taken into consideration. For instance, the process of theses' writing and guidance will be activated on the deadline of proposal submission, and will be frozen on the deadline of final draft submission. An example 
of the time-triggered rule is shown in Fig. 2.

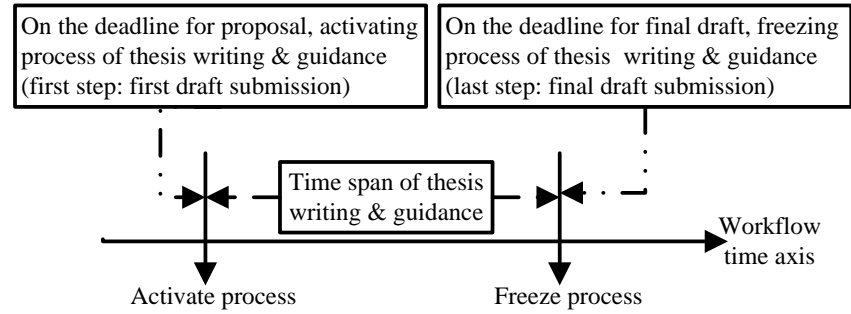

Fig. 2. An example of time-triggered rule.

Furthermore, each stage of theses' writing and guidance process need to be set a deadline for the efficient supervision; however, theses' writing and guidance are repeated between two roles of student and supervisor. The efficiency of each user to write or review a draft is different, so the deadline cannot be set congruously. The deadline of paper submitting and review is flexible, ensuring that online thesis guidance is more humanized and orderly.

The theses work process is a special workflow, and the subsequent task of some process is waiting for the prior task to finish, so that the task-based principle is also taken into consideration in the RBAC Workflow model. For example, the theses' review of the first drafts for supervisors will be activated after students submit their first drafts. When this process is done, it will activate students to submit the revised drafts. An example of the task-based rule is shown in Fig. 3.

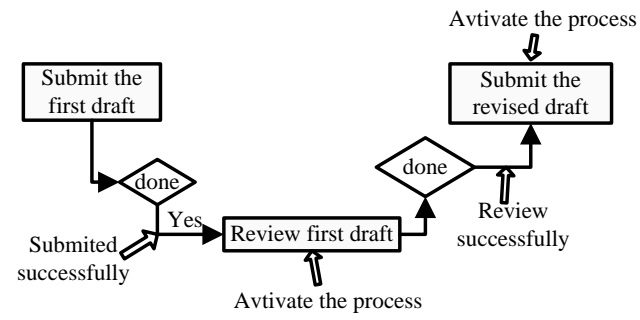

Fig. 3. Diagram of task-based principle.

To summarize, the application of time-triggered rule and task-based rule match the permissions' operation and task assignment.

\subsection{The RBAC Workflow Model for Thesis Management}

We present the RBAC Workflow model for thesis management. We build our models over the well-known RBAC96 [15] framework. The main components of the RBAC Workflow Model are users, sessions, roles, role

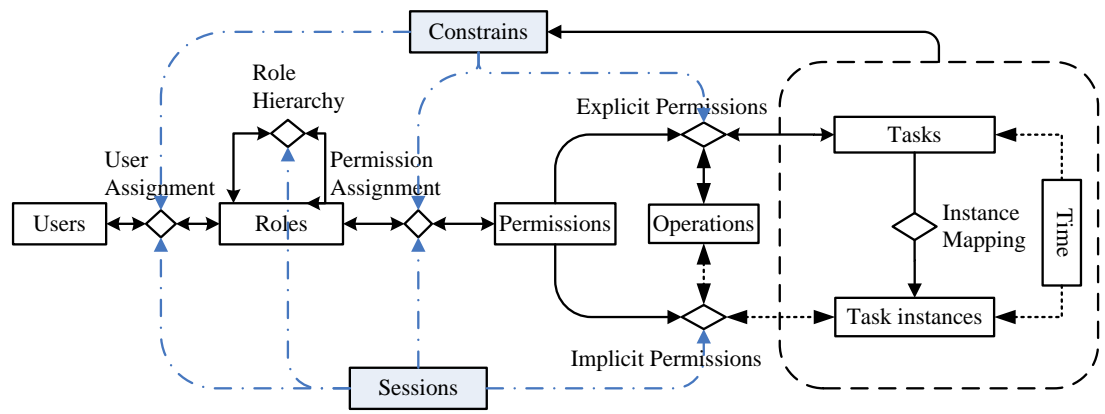

Fig. 4. The RBAC workflow model for thesis management.

Hierarchy, permissions, user assignment relationship, permission assignment relationship and constraints. Fig. 4 illustrates the RBAC Workflow Model.

MODEL: 
$\mathrm{U}$ - set of users, $\mathrm{R}$ - set of roles,

$\mathrm{P}$ - set of permissions,

TT - set of tasks, TI - set of task instances,

$\mathfrak{J}$ - An instance mapping [15] that maps each task to its instances

$\mathrm{UA} \subseteq \mathrm{U} \times \mathrm{R}$ (User Assignment)

$\mathrm{RH} \subseteq \mathrm{R} \times \mathrm{R}$ is a partial order on $\mathrm{R}$ also called the role hierarchy or Role dominance relation written as $\leq$

$\mathrm{PA} \subseteq \mathrm{R} \times \mathrm{P}$ (Permission Assignment)

$\mathrm{OP}=\{$ execute $\}$ (singleton set which contains the execute operation)

$\mathfrak{J}: \mathrm{TT} \rightarrow 2 \mathrm{TI}$

For example: $\mathfrak{J}(\mathrm{a}) \cap \mathfrak{J}(\mathrm{b})=\varphi$ if $\mathrm{a} \neq \mathrm{b}$ and $\mathrm{a}, \mathrm{b} \in \mathrm{TT}$

EP (set of EXPLICIT PERMISSIONS) $=\mathrm{OP} \times \mathrm{TT}$

IP $($ set of IMPLICIT PERMISSIONS $)=\mathrm{OP} \times \mathrm{TI}$

$\mathrm{P}($ set of permissions $)=\mathrm{EP} \cup \mathrm{IP}$

EPA (set of explicitly assigned permissions) $=\mathrm{R} \times \mathrm{EP}$

IPA (set of implicitly assigned permissions derived from EPA)

$\mathrm{IPA}=\{($ ri, execute, ti) $\mid[\exists($ ri, execute, $\mathrm{t}) \in \mathrm{EPA}] \wedge \mathrm{ti} \in \mathfrak{J}(\mathrm{t})\}$

PA (Permission Assignment) $=$ EPA U IPA

roles $(\mathrm{u}): \mathrm{U} \rightarrow 2 \mathrm{R}$, a function mapping each user to a role.

senior(r) : $\mathrm{R} \rightarrow 2 \mathrm{R}$, a function mapping a role to all its senior roles in role hierarchy.

permissions: $R \rightarrow 2$ IP, a function mapping each role $r$ to a set of permissions.

permissions*: $\mathrm{R} \rightarrow$ 2IP, extends permissions in presence of a role-hierarchy.

permissions $($ ri $)=\{($ execute, ti $) \mid(\exists[($ ri, execute, $\mathrm{t}) \in \mathrm{EPA}] \wedge \mathrm{ti} \in \mathfrak{J}(\mathrm{t})\}$

permissions $*(r i)=\{($ execute, $\mathrm{ti}) \mid(\exists \mathrm{r} \leq \mathrm{ri})[(\mathrm{r}$, execute, $\mathrm{t}) \in \mathrm{EPA}] \wedge \mathrm{ti} \in \mathfrak{J}(\mathrm{t})\}$

Constraints are predicates, which applied to various components, determine if its value is acceptable or not.

In the RBAC Workflow model for thesis management, a user may have different roles, but one user can only be assigned one role at the same time, that means we must assign a role to a user accurately. Therefore, we design an algorithm for user assignment as follows.

User assignment Algorithm

Illustration: assign roles to user.

Input: User as u.

Output: role's authorization to $\mathrm{u}$.

\{

Initialze: rArray;

rArray $=$ GetrArrayofUA(u);

If rArray is Null

Return NULL;

For each $r$ in rQueue

if $r$ match current status

Assign $r$ to $u$

Else

Next $r$

End for

If RSMaxC(u, rQueue)

// if out of bound of the rQueue which can be assigned to $u$.

Return NULL;

\}

The thesis workflow moves forward automatically and chronologically, and the access control permission of 
each stage work task is different in different period, so we design an algorithm for permission assignment as follows.

Permission assignment of the current task access Algorithm

Illustration: the permission of the role access the current task.

Input: Role as $r$, Task AS t,

Output: permission's authorization to $\mathrm{r}$.

\{

If $(r, t) \rightarrow(R, T T, P A)$ is NULL

Return NO PREMISSION;

Else

If Activate ( $\mathrm{t}$ )

Return READ \& WRITE;

Else

Return READ ONLY;

\}

The thesis management system based on the RBAC Workflow Model is currently available. The comparison of this system with the traditional manual way is structured as follows: Section IV.

\section{Application Studier and Comparisons}

To evaluate the efficiency of deploying the Thesis Management System based on the RBAC Workflow model (TMS-RW) when solving problems which exist in a manual way traditionally, we present the comparison of the application studies between the thesis management system and the traditional manual way, in section IV-A. Then, we present the comparison of mental workload evaluation after the Managements finish the same work of P1 and P5-P7 in Table 1 through the TMS-RW and the simulated traditional manual way in section IV-B. Finally, we present the results of the questionnaires about our thesis management system in section IV-C. In addition, our Thesis Management System based on the RBAC Workflow model is currently available at http://202.202.121.101/pdms.

Table 1. Time for Each Management Stage

\begin{tabular}{|c|c|c|c|c|c|}
\hline \multirow{2}{*}{$\begin{array}{l}\text { work } \\
\text { stage }\end{array}$} & \multicolumn{3}{|c|}{ Traditional Manual Way } & \multicolumn{2}{|c|}{ TMS-RW } \\
\hline & 2011 & 2012 & 2013 & 2014 & 2015 \\
\hline P1 & 2.5 days & 3 days & 3 days & $3.2 \mathrm{~min}$ & $2.8 \mathrm{~min}$ \\
\hline P2 & $20-30 \mathrm{~min} /$ time & $20-30 \mathrm{~min} /$ time & $20-30 \mathrm{~min} /$ time & $0.13 \mathrm{sec} /$ time & $0.12 \mathrm{sec} /$ time \\
\hline P3 & $20-30 \mathrm{~min} /$ time & $20-30 \mathrm{~min} /$ time & $20-30 \mathrm{~min} /$ time & $0.11 \mathrm{sec} /$ time & $0.132 \mathrm{sec} /$ time \\
\hline $\mathrm{P} 4$ & $20-30 \mathrm{~min} /$ time & $20-30 \mathrm{~min} /$ time & $20-30 \mathrm{~min} /$ time & $0.14 \mathrm{sec} /$ time & -— \\
\hline P5 & 2days & 2 days & 2 days & $3.7 \mathrm{~min}$ & -— \\
\hline P6 & 1day & 1 day & 1day & $0.54 \mathrm{sec}$ & -— \\
\hline P7 & $10-20 \mathrm{~min} /$ time & $10-20 \mathrm{~min} /$ time & $10-20 \mathrm{~min} /$ time & $0.12 \mathrm{sec} /$ time & - - \\
\hline
\end{tabular}

Illustration of Table 1: P1-assign supervisors, P2-count numbers of submitting Thesis-writing Plan on time, P3-count numbers of submitting Thesis Proposals on time, P4-count numbers of submitting Final Drafts on time, P5-divide groups for thesis defense, P6-count results, P7-search for students' documents. From p2 to p4, it needs to list the students' names who do not submit papers on time. The data of 2011 to 2013 is provided by the Teaching Secretary and Department Head who collect the data based on their actual work. The data of 2014 and 2015 we use is from the average data we calculate 20 times. In addition, it needs to handle special incidents (such as individual assignment) in P1 and P5. The thesis work of the undergraduates who are going to graduate in 2015 has been completed partially, therefore, the data here is only from P1 to P3. 
Table 2. The Number of Submission On Time

\begin{tabular}{|c|c|c|c|c|c|c|c|c|c|c|c|c|c|}
\hline \multirow{3}{*}{\multicolumn{2}{|c|}{$\begin{array}{l}\text { work } \\
\text { stage }\end{array}$}} & \multicolumn{9}{|c|}{ Traditional Manual Way } & \multirow{2}{*}{\multicolumn{3}{|c|}{$\begin{array}{c}\text { TMS-RW } \\
2014\end{array}$}} \\
\hline & & \multicolumn{3}{|c|}{2011} & \multicolumn{3}{|c|}{2012} & \multicolumn{3}{|c|}{2013} & & & \\
\hline & & $\begin{array}{c}\text { Total } \\
\text { number }\end{array}$ & $\begin{array}{l}\text { Submit } \\
\text { on time }\end{array}$ & Percent & $\begin{array}{c}\text { Total } \\
\text { number }\end{array}$ & $\begin{array}{l}\text { Submit } \\
\text { on time }\end{array}$ & Percent & $\begin{array}{c}\text { Total } \\
\text { number }\end{array}$ & $\begin{array}{l}\text { Submit } \\
\text { on time }\end{array}$ & Percent & $\begin{array}{c}\text { Total } \\
\text { number }\end{array}$ & $\begin{array}{l}\text { Submit } \\
\text { on time }\end{array}$ & Percent \\
\hline & S1 & 141 & 120 & $85.1 \%$ & 145 & 114 & $78.6 \%$ & 146 & 117 & $80.1 \%$ & 143 & 139 & $97.2 \%$ \\
\hline & S2 & 571 & 472 & $82.7 \%$ & 563 & 501 & $89.0 \%$ & 579 & 498 & $86.0 \%$ & 541 & 524 & $96.9 \%$ \\
\hline & S3 & 571 & 469 & $82.1 \%$ & 563 & 468 & $83.1 \%$ & 579 & 472 & $81.5 \%$ & 541 & 540 & $99.8 \%$ \\
\hline & S4 & 571 & 473 & $82.8 \%$ & 563 & 439 & $78.0 \%$ & 579 & 472 & $81.5 \%$ & 541 & 537 & $99.3 \%$ \\
\hline \multirow{6}{*}{ S5 } & S5-1 & - & -- & -- & - - & -- & -- & - - & -- & -- & 541 & 495 & $91.5 \%$ \\
\hline & S5-2 & -- & -- & - - & -- & - - & -- & -- & -- & -- & 541 & 533 & $98.5 \%$ \\
\hline & S5-3 & -- & -- & -- & -- & -- & -- & -- & -- & - - & 541 & 531 & $98.2 \%$ \\
\hline & S5-4 & -- & -- & -- & -- & -- & -- & - - & - - & -- & 541 & 504 & $93.2 \%$ \\
\hline & S5-5 & - - & -- & -- & -- & - & -- & - - & -- & -- & 541 & 539 & $99.6 \%$ \\
\hline & S5-6 & -- & - - & -- & -- & -- & - - & -- & - - & -- & 541 & 519 & $95.9 \%$ \\
\hline \multicolumn{2}{|c|}{ S6 } & 571 & 483 & $84.6 \%$ & 563 & 453 & $80.5 \%$ & 579 & 463 & $80.0 \%$ & 541 & 531 & $98.2 \%$ \\
\hline \multicolumn{2}{|c|}{ S7 } & 571 & 476 & $83.4 \%$ & 563 & 468 & $83.1 \%$ & 579 & 501 & $86.5 \%$ & 541 & 529 & $97.8 \%$ \\
\hline \multicolumn{2}{|c|}{ S8 } & 571 & 483 & $84.6 \%$ & 563 & 455 & $80.8 \%$ & 579 & 510 & $88.1 \%$ & 541 & 535 & $98.9 \%$ \\
\hline
\end{tabular}

Illustration of table 2: S1-topic, S2-select topic, S3-the Thesis-writing plan, S4-the Thesis Proposal, S5-Thesis' writing and guidance, S5-1-the Thesis Outline, S5-2-review the Thesis Outline, S5-3-the First Draft, S5-4-review the First Draft, S5-5-the Revised Draft, S5-6-review the Revised Draft, S6-the Final Draft, S7-review and mark the Final Draft, S8-review and mark the Final Draft crossly. Because the process of thesis' writing and guidance cannot be recorded, there are no any data of the process in the traditional manual way. Since the Revised Drafts may be submitted and reviewed repeatedly, the numbers shown in table 2 is collected when the first Revised Draft is submitted and reviewed from S5-5 to S5-6.

Table 3. The Data of Stored Documents

\begin{tabular}{|c|c|c|c|c|c|c|c|c|}
\hline \multirow{4}{*}{$\begin{array}{l}\text { Type } \\
\begin{array}{l}\text { Thesis writing } \\
\text { plan }\end{array}\end{array}$} & \multicolumn{6}{|c|}{ Traditional Way } & \multicolumn{2}{|c|}{ TMS-RW } \\
\hline & \multicolumn{3}{|c|}{ sum } & \multicolumn{3}{|c|}{ Slip-up } & sum & Slip-up \\
\hline & 2011 & 2012 & 2013 & 2011 & 2012 & 2013 & \multicolumn{2}{|c|}{2014} \\
\hline & 571 & 563 & 579 & 2 & 5 & 4 & 541 & 0 \\
\hline Thesis Proposal & 571 & 563 & 579 & 8 & 7 & 5 & 541 & 0 \\
\hline Thesis Outline & 0 & 0 & 0 & 0 & 0 & 0 & 958 & 0 \\
\hline First Draft & 0 & 0 & 0 & 0 & 0 & 0 & 943 & 0 \\
\hline Revised Draft & 0 & 0 & 0 & 0 & 0 & 0 & 4367 & 0 \\
\hline Final Draft & 571 & 563 & 579 & 10 & 8 & 11 & 541 & 0 \\
\hline Review & 571 & 563 & 579 & 4 & 7 & 6 & 541 & 0 \\
\hline cross review & 571 & 563 & 579 & 21 & 19 & 25 & 541 & 0 \\
\hline on file & 571 & 563 & 579 & 11 & 7 & 8 & 541 & 0 \\
\hline Storage way & paper & ument & ccupy & ace $a b$ & t $3.14 \mathrm{n}$ & & $\begin{array}{r}\text { hard disk } \\
5.15\end{array}$ & usage \\
\hline
\end{tabular}

\subsection{Application Studies}

The theses-completing data from 2011 to 2013 which is provided by the School of International Studies in Southwest University (of China) has been collected for the traditional manual way, while the theses-completing 
data in 2014 has been collected for the TMS-RW.

First, we present the time consumption of each management stage, which is shown in Table 1.

Second, we present the numbers of submitting drafts on time, which is shown in Table 2.

Third, we present the information of document storage and slip-up, which is shown in Table 3.

Fourth, we present the information of handling the special incidents about shifting responsibility between supervisors and students, which is shown in Table 4.

Table 4. The Data of Shifting Responsibilities

\begin{tabular}{|l|c|c|c|c|c|c|}
\hline \multirow{2}{*}{ Event } & \multicolumn{3}{|l|}{ Traditional Manual Way } & \multicolumn{2}{|c|}{ TMS-RW } \\
\cline { 2 - 4 } & \multicolumn{3}{|c|}{ times } & handle & times & handle \\
\cline { 2 - 5 } \cline { 2 - 4 } $\begin{array}{l}\text { shifting } \\
\text { responsibility }\end{array}$ & 8 & 5 & 6 & $\begin{array}{l}\text { Difficultly handle } \\
\text { without any record }\end{array}$ & 3 & $\begin{array}{c}\text { Easily handle } \\
\text { with records }\end{array}$ \\
\hline
\end{tabular}

Table 5. The Mental Work Load Evaluation

\begin{tabular}{|c|c|c|c|c|c|c|c|c|}
\hline \multirow{2}{*}{\multicolumn{3}{|c|}{ Group }} & \multicolumn{4}{|c|}{ short-term memory } & \multicolumn{2}{|c|}{ digital computation } \\
\hline & & & \multirow{2}{*}{$\frac{\text { time }}{3 \mathrm{~s}}$} & \multirow{2}{*}{$\frac{\text { accuracy }}{69.7 \%}$} & \multirow{2}{*}{$\frac{\text { time }}{6 \mathrm{~s}}$} & \multirow{2}{*}{$\frac{\text { accuracy }}{39.2 \%}$} & \multirow{2}{*}{$\begin{array}{c}\text { time } \\
41 " 78\end{array}$} & \multirow{2}{*}{$\frac{\text { accuracy }}{100 \%}$} \\
\hline \multirow{9}{*}{ M1 } & \multicolumn{2}{|c|}{ Normal Case } & & & & & & \\
\hline & \multirow{4}{*}{ TMS-RW } & P1 & $3 s$ & $68.8 \%$ & $6 s$ & $39.5 \%$ & $40 " 93$ & $100 \%$ \\
\hline & & P5 & $3 \mathrm{~s}$ & $67.4 \%$ & $6 s$ & $38.6 \%$ & $42 " 48$ & $100 \%$ \\
\hline & & P6 & $3 \mathrm{~s}$ & $69.9 \%$ & $6 s$ & $39.2 \%$ & $41 " 55$ & $95 \%$ \\
\hline & & P7 & $3 \mathrm{~s}$ & $70.5 \%$ & $6 s$ & $37.8 \%$ & $42 " 08$ & $100 \%$ \\
\hline & \multirow{4}{*}{$\begin{array}{l}\text { Simulate } \\
\text { traditional } \\
\text { manual } \\
\text { way }\end{array}$} & P1 & $3 s$ & $41.2 \%$ & $6 s$ & $20.8 \%$ & $66 " 26$ & $75 \%$ \\
\hline & & P5 & $3 \mathrm{~s}$ & $45.5 \%$ & $6 s$ & $21.2 \%$ & 68"11 & $70 \%$ \\
\hline & & P6 & $3 \mathrm{~s}$ & $49.2 \%$ & $6 s$ & $24.5 \%$ & $57 " 54$ & $85 \%$ \\
\hline & & P7 & $3 \mathrm{~s}$ & $67.6 \%$ & $6 s$ & $38.4 \%$ & $43 " 93$ & $95 \%$ \\
\hline \multirow{9}{*}{ M2 } & \multicolumn{2}{|c|}{ Normal Case } & $3 \mathrm{~s}$ & $70.2 \%$ & $6 s$ & $37.7 \%$ & $45 " 13$ & $100 \%$ \\
\hline & \multirow{4}{*}{ TMS-RW } & P1 & $3 \mathrm{~s}$ & $68.5 \%$ & $6 s$ & $37.4 \%$ & 48"09 & $95 \%$ \\
\hline & & P5 & $3 s$ & $71.6 \%$ & $6 s$ & $37.8 \%$ & $46 " 72$ & $100 \%$ \\
\hline & & P6 & $3 \mathrm{~s}$ & $69.8 \%$ & $6 s$ & $36.1 \%$ & $44 " 10$ & $100 \%$ \\
\hline & & P7 & $3 \mathrm{~s}$ & $71.2 \%$ & $6 s$ & $36.6 \%$ & $46 " 08$ & $95 \%$ \\
\hline & \multirow{4}{*}{$\begin{array}{l}\text { Simulate } \\
\text { traditional } \\
\text { Manual } \\
\text { Way }\end{array}$} & P1 & $3 \mathrm{~s}$ & $40.8 \%$ & $6 s$ & $21.9 \%$ & $73 " 42$ & $70 \%$ \\
\hline & & P5 & $3 \mathrm{~s}$ & $43.1 \%$ & $6 s$ & $22.2 \%$ & 69"21 & $75 \%$ \\
\hline & & P6 & $3 s$ & $47.9 \%$ & $6 s$ & $25.8 \%$ & $65 " 87$ & $80 \%$ \\
\hline & & P7 & $3 \mathrm{~s}$ & $70.1 \%$ & $6 s$ & $36.7 \%$ & $49 " 52$ & $95 \%$ \\
\hline
\end{tabular}

\subsection{Evaluation of Mental Workload}

We do mental workload evaluation of short-term memory and digital computation on two Managements (M1, male, 37 years old; M2, female, 33 years old) after they complete the work of P1 and P5-P7 in Table1 through the TMS-RW. In the meantime, we do the same mental workload evaluation on the two managers when they are in the normal situation. And another situation is that they complete the work of P1 and P5-P7 in Table1 through the simulated traditional manual way. We do short-term memory test on each management with 9 sets of phrases which have the same difficulty level, then do digital computation test on each management with 9 sets of digital questions, and there are 20 questions in each set, which have the same difficulty level as well. Table 5 shows the results of the mental workload evaluation.

\subsection{Questionnaire}

After the thesis teaching task completed in 2014, we sent questionnaires about the TMS-RW to managements, 
teachers and students respectively. The results of the questionnaire are structured as in Table 6.

Table 6. Questionnaires

\begin{tabular}{|l|c|c|c|c|c|c|}
\hline \multirow{2}{*}{ Group } & \multicolumn{2}{|c|}{ management } & \multicolumn{2}{c|}{ teacher } & \multicolumn{2}{c|}{ student } \\
\cline { 2 - 7 } & $\mathrm{P}$ & $\mathrm{N}$ & $\mathrm{P}$ & $\mathrm{N}$ & $\mathrm{P}$ & $\mathrm{N}$ \\
\hline Send & 8 & - & 140 & - & 540 & - \\
\hline Collect & 8 & 0 & 138 & 2 & 527 & 13 \\
\hline Reduce workload & 8 & 0 & 127 & 11 & - & - \\
\hline Supervise method & 8 & 0 & 138 & 0 & 525 & 2 \\
\hline Theses Guide method & - & - & 125 & 13 & 498 & 29 \\
\hline Draft Submit method & 8 & 0 & 138 & 0 & 527 & 0 \\
\hline Storage method & 8 & 0 & 138 & 0 & 527 & 0 \\
\hline Pro the use of the system & 8 & 0 & 134 & 4 & 525 & 2 \\
\hline
\end{tabular}

Illustration: P-positive, N-negative.

\subsection{Discussion}

Table 1 demonstrates that completing the same work by TMS-RW costs less time and Table 5 shows that the evaluation of mental workload about the TMS-RW is closer to the normal case. In addition, the results of the questionnaires about the TMS-RW to managers and teachers indicate that a majority of them take a positive attitude to the result that the TMS-RW can reduce the thesis workload, so that we can conclude that the thesis management system via RBAC Workflow model can reduce the workload about thesis management work.

Table 2 shows that the proportion of submission on time in the whole process of theses' writing and guidance by TMS-RW is high.

Table 3 shows the submission number of first drafts and revised drafts is over 5000. Both tables imply that teachers and students communicate with each other more frequently and conveniently during the process of theses writing and guidance, thus, it can be inferred that the communication between supervisors and students become convenient by the TMS-RW.

The data in Table 2 and Table 3 indicate that the TMS-RW can record the whole process of thesis management. It is very easy to handle the special incidents of shifting responsibility through the records of the thesis writing and guidance process in Table 4, in addition, most of the users agree with the result that the TMW-RW can provide a method to supervise for thesis management according to the questionnaires, thus, it can be inferred that the TMW-RW can provide a method to supervise for thesis management.

The numbers in Table 3 show that the TMS-RW stores a great deal of electronic documents, and cut down the slip-up conditions. In addition, the storage way is of very low-carbon and easy to search. Furthermore, the data, that is the records of the whole thesis work process, could provide some bases for performance-related evaluation on teaching.

To summarize, it can be convinced that the TMS-RW can enhance the informatization level of undergraduate thesis work greatly.

\section{Conclusion}

In this paper, we have presented a RBAC Workflow model for the thesis management process and the prototype thesis management system based on the RBAC Workflow model which is currently available. The thesis management system can simplify the thesis management process, successfully solving those problems which exist in the traditional manual way and managing the work of undergraduate theses conveniently which can save a large number of data. In addition, this study could make a contribution to Software Engineering Education. 
Unfortunately, thesis management system based on the RBAC Workflow model cannot ensure that it can enhance the quality of the undergraduate theses. This problem could be solved if we consider the development of cultural data bank, where sources are provided by teachers. Besides, this prototype system just serves the School of International Studies of Southwest University in China. If spreading this system among more universities, the optimization algorithm needs to be considered.

\section{Acknowledgment}

This paper is supported by the fundamental research grants of Southwest University XDJK2012C024. We thank the reviewers for their helpful comments.

\section{References}

[1] Xun, J., Liu, Z., \& Gu, N. (2004). Paper Management System based on ontology. Computer Engineering, 3(6), 38-41

[2] Yu D. H., Yan, D. Y., \& Fang, P. (2007). Study on web management of graduation thesis. Journal of Beijing Institute of Technology (School Sicences Edition), (4),143-144.

[3] Mao, H. B., Yin, De, S., Guo, J., \& Zhou, A. H. (2010). Research and design of the graduation design(Thesis) intelligent management system based on net. Modern Educational Technology, (10),128-131.

[4] Li, Z. H., Wang, Y., \& Li, W. (2011). Research of academic thesis management system based on web. Modern Educational Technology, (2),125-128.

[5] Wen, X. Yong. (2012). Design and implementation of gradutaion thesis management system based on workflow and role collaboration. Research and Exploration in Laboratory, 4(4), 314-317

[6] Long, S. R., Zhao, X. K., \& Cen, L. (2013). Design a thesis management system based on Browser/Server and workfolw. Computer Knowledge and Technology, 9(14), 3306-3307.

[7] Sandhu, R., Coyne, E. J., Feinstein, H. L., \& Youman, C. E. (1996). Role-based access control models. IEEE Computer, 29(2), 38-47.

[8] Zhang, X. W., Sejong, O., \& Ravi, S. (2003). PBDM: A flexible delegation model in RBAC. Proceedings of the Eighth ACM Symposium on Access Control Models and Technologies (pp. 149-157).

[9] Christine, L. (2005). A faster way to temporarily redirect the role based access control workflow processes. Proceeding of 21st Computer Science Seminar.

[10] David, H. (1995). Workflow management coalition. The workflow Reference Model. Hampshire, UK: Workflow Management Coalition.

[11] Pont, M. J. (2001). Patterns for Time-Triggered Embedded Systems, Harlow, England: Addison-Wesley.

[12] Leen, G., \& Hefferman, D. (2002). TTCAN: A new time-triggered controller area network. Microprocessors and Microsystems, 2, 77-94.

[13] Rod, E. (2003). Task-based language learning and teaching. The Electronic Journal for English as a Second Language.

[14] Peter, S. (1996). A Framework for the Implementation of task-based Instruction. Applied Linguistics, 1,38-62.

[15] Kandala, S., \& Sandhu, R. (2001). Secure role-based workflow models. Database and Application Security XV, Springer.

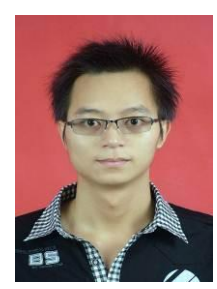

Kui Liu was born in 1988. He received his master's degree in computer application technology in Southwest University of China in 2013.

Now, He is working in Southwest University of China and he is a teaching assistant. His research interests include data mining and online education. 
Zhurong Zhou was born in 1970. He received his $\mathrm{PhD}$ in computer science in Southwest University of China.

Now, He is working as an associate professor in Southwest University of China. His research interests include data mining, semantic network, search engine and online education.

Qianguo Chen was born in 1986. He received his master's degree in computer application technology in Southwest University of China in 2013.

He is working in Chongqing Technology and Business University of China and he is a teaching assistant. He research interests data mining and online education.

Xiaoli Yang was born in 1978. He received his a master's degree in computer application technology in Southwest University of China in 2004.

He is working in Southwest University of China as a lecturer. His research interests include deducational technology and online education. 